Int. J. Electrochem. Sci., 15 (2020) 10866 - 10884

\title{
Fuzzy Predictive Energy Management for Hybrid Energy Storage Systems of Pure Electric Vehicles using Markov Chain Model
}

\author{
Qiao Zhang ${ }^{1, *}$, Lijia Wang ${ }^{1}$, Gang Li $^{1}$ and Shaoyi Liao ${ }^{2}$ \\ ${ }^{1}$ School of Automobile and Traffic Engineering, Liaoning University of Technology, Jinzhou 121000, \\ China \\ ${ }^{2}$ Information systems Department, City University of Hong Kong, Hong Kong, 999077, China. \\ Corresponding author: Q. Zhang \\ *E-mail: zq_625@163.com
}

doi: $10.20964 / 2020.11 .70$

Received: 21 July 2020 / Accepted: 13 September 2020 / Published: 30 September 2020

\begin{abstract}
This paper describes a fuzzy predictive energy management strategy for battery and supercapacitor hybrid energy storage systems of electric vehicles and validates it using a scaled down experimental test platform. The strategy consists of a power demand distributor for dealing with power flow between battery and supercapacitor and a power demand predictor for improving the control performance of the former. The power demand distributor is developed based on a combination of filtration strategy and fuzzy logic controller. The filtration strategy is used to prevent battery from providing high frequency power demand. The fuzzy logic controller is used to shave battery peak current and maintain the voltage level of supercapacitor. Considering the stochastic nature of actual traffic condition, the power demand predictor is developed using a Markov chain model. Different from prior research efforts that carry out Markov decisions using either weighted probability estimation or maximum probability estimation, this study implement a comparative study on the two probability estimation methods based on NEDC, NurembergR36 and SC03 driving cycles. Experimental results validated the superiority of the described control strategy.
\end{abstract}

Keywords: Battery, supercapacitor, hybrid energy storage system, Markov decisions.

\section{FULL TEXT}

(C) 2020 The Authors. Published by ESG (www.electrochemsci.org). This article is an open access article distributed under the terms and conditions of the Creative Commons Attribution license (http://creativecommons.org/licenses/by/4.0/). 